\title{
Biosensing Membrane Base on Ferulic Acid and Glucose Oxidase for an Amperometric Glucose Biosensor
}

\author{
Gabriela Valdés-Ramírez *(D) and Laura Galicia * \\ Chemistry Department, Universidad Autónoma Metropolitana Unidad Iztapalapa, Av. San Rafael Atlixco 186, \\ Leyes de Reforma 1ra Secc., 09340 Ciudad de Mexico, Mexico \\ * Correspondence: gabrivra@gmail.com (G.V-R.); lgl@xanum.uam.mx (L.G.)
}

Citation: Valdés-Ramírez, G.; Galicia, L. Biosensing Membrane Base on Ferulic Acid and Glucose Oxidase for an Amperometric Glucose Biosensor. Molecules 2021, 26, 3757. https:// doi.org/10.3390/molecules26123757

Academic Editor: Antonella Curulli

Received: 31 May 2021

Accepted: 17 June 2021

Published: 20 June 2021

Publisher's Note: MDPI stays neutral with regard to jurisdictional claims in published maps and institutional affiliations.

Copyright: (c) 2021 by the authors. Licensee MDPI, Basel, Switzerland. This article is an open access article distributed under the terms and conditions of the Creative Commons Attribution (CC BY) license (https:// creativecommons.org/licenses/by/ $4.0 /)$.

\begin{abstract}
A biosensing membrane base on ferulic acid and glucose oxidase is synthesized onto a carbon paste electrode by electropolymerization via cyclic voltammetry in aqueous media at neutral $\mathrm{pH}$ at a single step. The developed biosensors exhibit a linear response from 0.082 to $34 \mathrm{mM}$ glucose concentration, with a coefficient of determination $\mathrm{R}^{2}$ equal to 0.997 . The biosensors display a sensitivity of $1.1 \mu \mathrm{AmM}^{-1} \mathrm{~cm}^{-2}$, a detection limit of $0.025 \mathrm{mM}$, and $0.082 \mathrm{mM}$ as glucose quantification limit. The studies reveal stable, repeatable, and reproducible biosensors response. The results indicate that the novel poly-ferulic acid membrane synthesized by electropolymerization is a promising method for glucose oxidase immobilization towards the development of glucose biosensors. The developed glucose biosensors exhibit a broader linear glucose response than other polymer-based glucose biosensors.
\end{abstract}

Keywords: ferulic acid; glucose oxidase; electropolymerization; glucose; electrochemical biosensor

\section{Introduction}

In the past years, glucose biosensors have been extensively used in the alimentary, environmental, and biomedical fields. In the biomedical industry, glucose biosensors are used as an important tool to monitor glucose in biological fluids allowing better management of diabetes, a pathology that is estimated to affect $7.7 \%$ of the population by 2030 [1-3]. In the food industry, glucose is also a target analyte in the production process $[4,5]$. Therefore, glucose biosensors development is a major goal of different research groups; the emphasis is on improving the analytical parameters of the existing biosensors, such as linearity covering low and high glucose concentrations and making their fabrication simple, portable, with a rapid and accurate response [1-3]. The improvement of analytical parameters can be achieved by modifications of the biosensing membrane synthesis, utilizing modified recognized elements, redox mediators, or nanomaterials, as well as using different immobilization methods by employing a variety of chemicals that allow the synthesis of strong biosensing membranes [1,3]. Knowing that biosensor performance is strongly dependent upon the enzyme immobilization process [6], several research groups have explored enzyme immobilization by electropolymerization utilizing conductive and non-conductive polymers [3,7-15].

This study presents the development of a glucose biosensor employing ferulic acid as a monomer for the synthesis of the biosensing membrane, with direct incorporation of glucose oxidase (GOx) as the biorecognition element and bovine serum albumin (BSA) as an enzyme stabilizer. The 3-methoxy-4-hydroxycinnamic acid, better known as ferulic acid (FA), is found at the plant cell wall and is the most abundant hydroxycinnamic acid in the plant kingdom [16]. It possesses anti-inflammatory, anticancer, and antioxidant properties; therefore, FA is widely used in the pharmaceutical and food industries [17-19]. Likewise, it has been incorporated into biocompatible materials with biomedical applications [20,21]. Due to FA abundance and applications, electrochemical methodologies to detect and quantify FA in real samples have been developed, with studies showing the possibilities 
of FA electropolymerization, which begins with the monomer oxidation and subsequent ortho-quinone/ortho-hydroquinone system formation, followed by a radical coupling reaction allowing the polymerization [21-26].

In the present study, the biosensing membranes are synthesized by electropolymerization onto a carbon paste electrode in aqueous media. To the best of our knowledge, this is the first time that ferulic acid has been used as a monomer to synthesize a biosensing membrane incorporating $\mathrm{GOx}$ as a biorecognition element to generate amperometric glucose biosensors.

\section{Results and Discussion}

\subsection{Ferulic Acid Electropolymerization}

Poly-ferulic acid membranes were synthesized by electropolymerization via cyclic voltammetry from -600 to $850 \mathrm{mV}, 20 \mathrm{mV} / \mathrm{s}$ scan rate during 10 cycles onto a CPE in $2.0 \mathrm{mM}$ FA solution prepared in $100 \mathrm{mM}$ acetate medium. Figure $1 \mathrm{~A}-\mathrm{C}$ shows the voltammetric responses for the first and second cycles of FA electropolymerization at three different $\mathrm{pH}$ conditions (A) 2.8, (B) 6.8, and (C) 9.6. For the acidic media at the forward scan, two oxidation signals with a maximum current at 260 and $660 \mathrm{mV}$ (Epa and Epa $\left.{ }_{\text {II }}\right)$ were exhibited. Nonetheless, at neutral and basic $\mathrm{pH}$, only one wide signal (Epa $)$ from -80 to $300 \mathrm{mV}$ was displayed. For the backward scans, there was a small reduction signal $\left(\mathrm{Epc}_{\mathrm{I}}\right)$ detected at all studied $\mathrm{pH}$ levels. At the second and successive cycles, the anodic current decreased rapidly, whereas the reduction currents persisted. The behavior is explained by the electrodeposition of a strongly passivating polymer layer onto the electrode surface; similar behavior was observed for phenols and aromatic amines electropolymerization $[3,10-12,15,27,28]$. Furthermore, at the three systems after the first cycle, a small oxidation at less positive potentials (Epa ${ }_{\text {III }}$ ) appeared (figures inset). Following FA electropolymerization, the modified CPEs were thoroughly rinsed with $100 \mathrm{mM}$ phosphate buffer pH 7.3 (PBS). Figure 1D shows typical voltammograms in PBS, before and after polyFA electropolymerization, the respective $\mathrm{pH}$ modification conditions are shown at the inset legend. For the bare $\mathrm{CPE}$, a flat voltammogram was observed, whereas at modified $\mathrm{CPE}$ (poly-FA CPE), two oxidation and one reduction peaks independent of $\mathrm{pH}$ were exhibited, Epa ${ }_{\text {I }}$ with a maximum current around $180 \mathrm{mV}$ associated to the remaining unattached monomer. $\mathrm{Epc}_{\mathrm{I}}$ and $\mathrm{Epa}_{\mathrm{III}}$ were taken as an indication of the presence of poly-FA membrane. Similar results were observed by da Silva [21]. The results showed that under our studied conditions, the electropolymerization of FA can take place at the three $\mathrm{pH}^{\prime} \mathrm{s}$ media and not only at aqueous acidic, aqueous basic, or organic media as was found by da Silva and Matsushita in their respective studies [21-23]. Considering the biosensor uses underphysiological conditions and to avoid $\mathrm{pH}$ changes from the biosensing membrane synthesis to its applications, enzyme immobilization was performed under neutral $\mathrm{pH}$ conditions in the presence of acetate. 

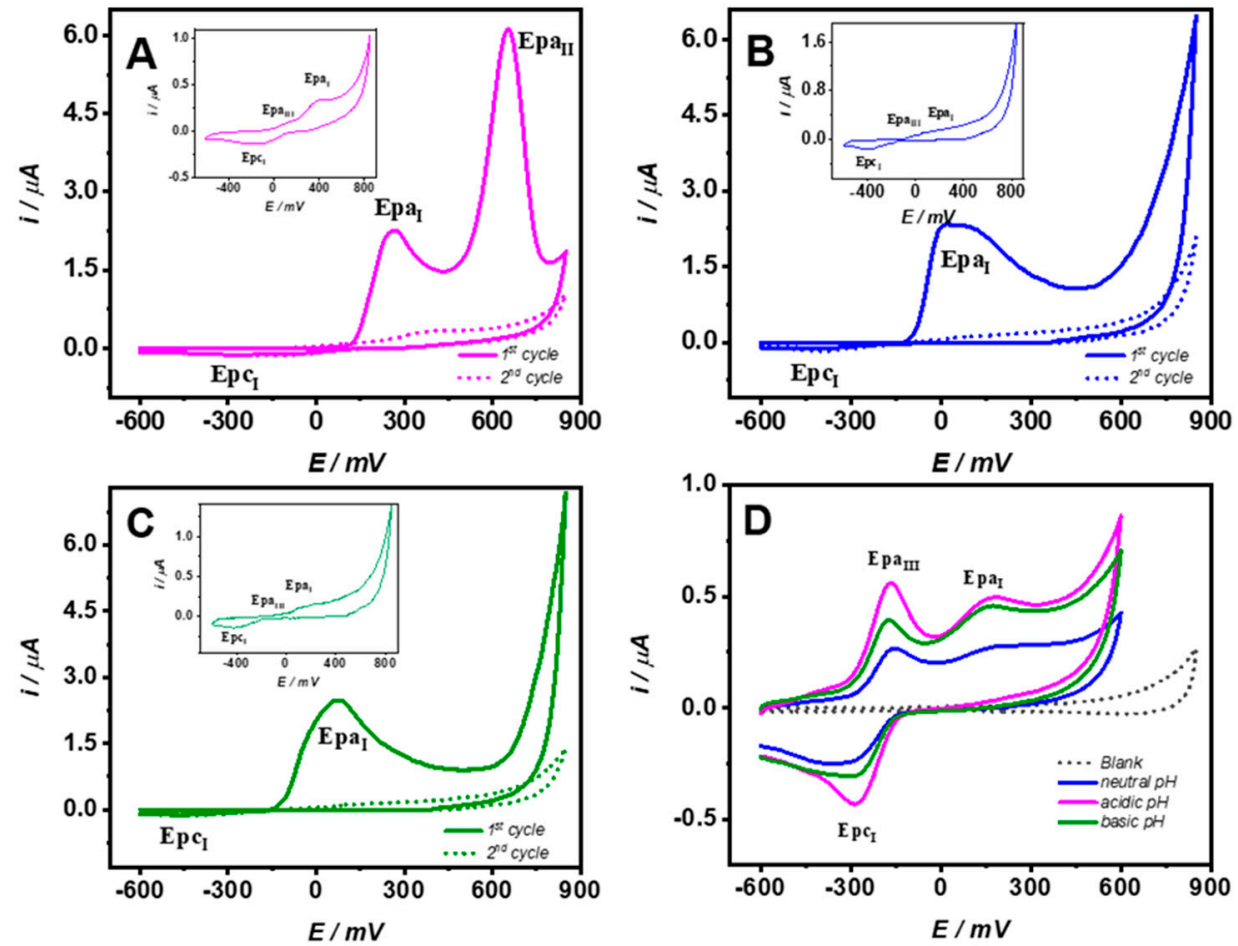

Figure 1. Cyclic voltammograms at the first and second cycles for ferulic acid electropolymerization, $2 \mathrm{mM}$ FA solution prepared at $100 \mathrm{mM}$ acetate at different $\mathrm{pH}$ values (A) 2.8, (B) 6.8, (C) 9.6, the insets show a zoom of the second cycle showing the Epa III signal. (D) Cyclic voltammogram in PBS at bare CPE and modified CPE with poly-FA synthesized at 2.8, 6.8, or $9.6 \mathrm{pH}$ conditions. All experiments were performed at $20 \mathrm{mV} / \mathrm{s}$.

\subsection{Ferulic Acid Electropolymerization}

Ferulic acid $2 \mathrm{mM}$ solution prepared in $100 \mathrm{mM}$ acetate $\mathrm{pH} 7.0$, containing $31.5 \mathrm{U} / \mathrm{mL}$ GOx and $0.05 \mathrm{mg} / \mathrm{mL}$ BSA was employed for biosensing membrane electropolymerization. The biosensing membrane was synthesized by cyclic voltammetry from -600 to $850 \mathrm{mV}$ at $20 \mathrm{mV} / \mathrm{s}$ scan rate, during 10 cycles. Figure $2 \mathrm{~A}$ shows the cyclic voltammogram from FA-GOx-BSA electropolymerization. After the first cycle, a decrease of the anodic peak current was observed; a similar performance was observed at other monomers such as aminophenol and phenylenediamine used for biosensors fabrication by electropolymerization $[3,10-12,15,27,28]$.

Following the electropolymerization, the unattached FA, GOx, and BSA were removed by rinsing the biosensors thoroughly with PBS. Glucose biosensors response was examined first by voltammetry. Figure 2B shows the linear sweep voltammetry (LSV) for glucose additions up to $47 \mathrm{mM}$ in PBS at $20 \mathrm{mV} / \mathrm{s}$. The results demonstrate that GOx was incorporated successfully into the poly-FA membrane by the electrochemical detection of the enzymatically produced $\mathrm{H}_{2} \mathrm{O}_{2}$, which can penetrate and diffuse through the biosensing layer, allowing glucose detection. The LSV shows that $\mathrm{H}_{2} \mathrm{O}_{2}$ oxidation began at $600 \mathrm{mV}$. Therefore, glucose calibrations were performed at $800 \mathrm{mV}$ constant potential in PBS. Figure $2 \mathrm{C}$ shows the typical current $v$ s time response for successive additions of glucose $4.9 \mathrm{mM}$. After each glucose addition, the current increased quickly to a steady-state, $90 \%$ of the maximum current was reached after $35 \mathrm{~s}$. The current was stable at least for the following $180 \mathrm{~s}$ showing good response stability at both low and high glucose concentrations. Figure 2D shows the average results for three consecutive glucose calibrations. The biosensors showed a linear response from 0.082 to $34 \mathrm{mM}$ glucose concentration covering the normal physiological conditions and the hypo and hyperglycemic ranges for human biofluids. The glucose biosensors sensitivity was $1.1 \mu \mathrm{AmM}^{-1} \mathrm{~cm}^{-2}$, the coefficient of determination was $\mathrm{R}^{2}=0.997$, and for three consecutive calibrations, the RSD was 
$1.57 \%$ showing acceptable operational stability. LOQ and LOD were 0.082 and $0.025 \mathrm{mM}$ calculated as $10 \sigma_{B} / b$ and $3 \sigma_{B} / b$, respectively [29]. The results demonstrate that the immobilization method employing FA as a monomer could be suitable for future applications on continuous glucose monitoring. Furthermore, the biosensors long-term operational stability was determined by performing daily glucose calibration in PBS. After 7 days, the maintained sensitivity was $64.3 \%$ of the initial amperometric response. The sensors were stored at room temperature in dry conditions while not in use. Similar synthesis conditions were employed to prepare and evaluate an independent set of five different biosensors; the coefficient of variation for the sensitivity of the biosensors at first glucose calibration was $3.6 \%$. The biosensors' selectivity was evaluated for two electroactive species present in human plasma under normal physiological conditions, $300 \mu \mathrm{M}$ of uric acid (UA) and $100 \mu \mathrm{M}$ of ascorbic acid (AA) at polyFA membrane by amperometry at $800 \mathrm{mV}$ in PBS. It was found that only 10 and $15 \%$ of the responses for UA and AA were generated compared to bare CPE. The signal is attributed to the high potential applied for the electrochemical detection. Yet, the poly-FA membrane synthesized at neutral $\mathrm{pH}$ could work as a permselective membrane; in this regard, a total rejection for AA and UA applying lower detection potential at poly-FA membranes synthesized at acidic conditions onto multi-wall carbon nanotubes were found [21].
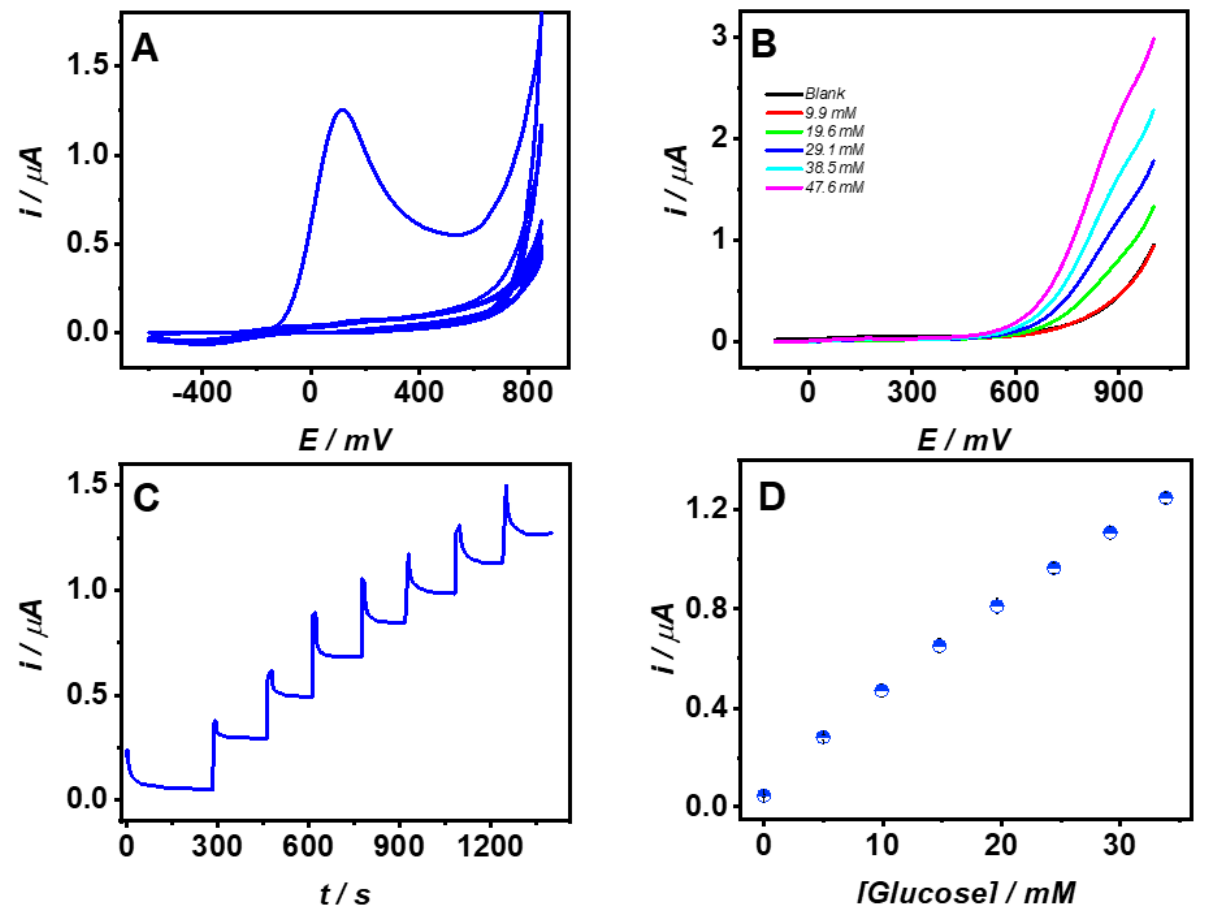

Figure 2. (A) Cyclic voltammogram for the synthesis (electropolymerization) of the biosensing membrane of poly-FA-GOx-BSA. (B) Linear voltammograms for biosensors at glucose evaluation in PBS. (C) Current vs time plot at $800 \mathrm{mV}$ for successive glucose $4.9 \mathrm{mM}$ additions (continues monitoring) in PBS. (D) Glucose response for three successive calibrations in PBS.

To evaluate the performance of the biosensor in the presence of proteins, the synthesized biosensors were used to perform glucose calibration in artificial interstitial fluid (a-ISF) prepared according to Fogh-Andersen [30]; $\mathrm{CO}_{2}$ was not added into the solution. The results showed that biosensor sensitivity in a-ISF decreased 20\%; nonetheless, the linearity was maintained up to $30 \mathrm{mM}$ glucose concentration, the sensitivity diminution could be associated with non-specific BSA adsorption. After glucose calibrations in a-ISF, the biosensors were washed and re-calibrated in PBS; $99.8 \%$ of the original sensitivity prevailed.

The analytical parameters of the developed glucose biosensors based on poly-FAGOx-BSA membrane show a competitive performance compared to other polymer-based biosensors. The biosensing membrane synthesized in this work excelled in the linear range. 
A comparison of the analytical parameters for the developed glucose biosensor and other polymer-based glucose biosensors is shown at Table 1.

Table 1. Comparison of polymer-based glucose amperometric biosensors.

\begin{tabular}{|c|c|c|c|c|}
\hline Material & Detection Limit & Linear Range & Sensitivity & Ref. \\
\hline PANI/GOx & $0.062 \mathrm{mM}$ & $1-10 \mathrm{mM}$ & $0.54 \mu \mathrm{A} \mathrm{mM}^{-1}$ & [8] \\
\hline Nanodiamond-g-PANI/GOx & $0.018 \mathrm{mM}$ & $1-30 \mathrm{mM}$ & $2.03 \mu \mathrm{A} \mathrm{mM}^{-1}$ & [8] \\
\hline PANI/MWCNTs/GOx/HRP & $0.02 \mathrm{mM}$ & $0.5-12 \mathrm{mM}$ & $0.94 \mu \mathrm{A} \mathrm{mM}^{-1}$ & [9] \\
\hline $\mathrm{Pt} / \mathrm{o}-\mathrm{PD} / \beta c y c l o d e x t r i n / G O x$ & $0.79 \mathrm{mM}$ & $2.5-15.5 \mathrm{mM}$ & $0.150 \mathrm{nA} \mathrm{mM}^{-1}$ & [10] \\
\hline $\mathrm{Ag} / \mathrm{p}$ (m-aminophenol) nanofibers & $0.062 \mu \mathrm{M}$ & $0.1-8.0 \mathrm{mM}$ & $17.45 \mu \mathrm{A} \mathrm{mM}^{-1} \mathrm{~cm}^{-2}$ & [11] \\
\hline $\mathrm{Pt} /$ poly(o-PD)/GOx & $0.020 \mathrm{mM}$ & $0-2 \mathrm{mM}$ & $0.140 \mathrm{nA} \mathrm{mM}^{-1}$ & [12] \\
\hline Polypyrrole/CNT/GOx & $0.005 \mathrm{mM}$ & $1-4.1 \mathrm{mM}$ & $54.2 \mu \mathrm{A} \mathrm{mM}^{-1} \mathrm{~cm}^{-2}$ & [13] \\
\hline $\mathrm{Pt} /$ poly $(\mathrm{o}-\mathrm{PD}) / \mathrm{GOx}$ & $0.100 \mathrm{mM}$ & $0-14 \mathrm{mM}$ & $353 \mu \mathrm{A} \mathrm{mM}^{-1}$ & [15] \\
\hline CPE/poly-FA-GOx-BSA & $0.025 \mathrm{mM}$ & $0.082-34 \mathrm{mM}$ & $1.1 \mu \mathrm{AmM}^{-1} \mathrm{~cm}^{-2}$ & This work \\
\hline
\end{tabular}

Usually, the polymer-based biosensors and others are saturated around $10 \mathrm{mM}$ glucose concentration. Thus, their use in samples where the glucose concentration is larger, such as samples from diabetic patients where glucose concentrations in the hyperglycemic conditions could be larger than $22 \mathrm{mM}$ glucose [31], and the use of other biosensing membranes is useless. In this regard, the developed biosensor in this work did not show saturation even at $34 \mathrm{mM}$ glucose concentration, making the use of the developed biosensing membrane attractive in improving the linear range of glucose biosensors employed in the biomedical field, either as strip sensors or continuous glucose monitoring sensors (CGM).

\section{Materials and Methods}

Ferulic acid, glucose oxidase, bovine serum albumin, glucose, ascorbic acid, and uric acid were purchase from Sigma-Aldrich; sodium acetate three hydrated, sodium chloride, potassium phosphate monobasic, potassium phosphate dibasic, and sodium chloride were purchase from J.T. Baker; graphite powder $99.99 \%$ purity was obtained from Alfa Aesar; and mineral oil was purchased from Fluka.

All chemicals were used as received without further purification. Ferulic, uric, and ascorbic acid solutions were daily prepared with Milli-Q water 18.2 M $\Omega$ and stored in the dark until used. To reach an equilibrium between glucose isomers, glucose stock solutions were prepared at least $48 \mathrm{~h}$ before use. Voltammetric and amperometric experiments were carried out at room temperature. The electrochemical working station was a BAS100 potentiostat employing a three-electrode system, where a platinum wire was used as a counter electrode, saturated mercury sulfate $\left(\mathrm{Hg} / \mathrm{Hg}_{2} \mathrm{SO}_{4 \mathrm{sat}}\right)$ was used as a reference electrode, and carbon paste electrode (CPE) or modified CPE was used as a working electrode.

Working electrodes were prepared from a homogeneous paste 1:1 mixture of graphite powder and mineral oil, the paste was firmly packed into a PVC tube that provided a geometrical surface area of $0.0314 \mathrm{~cm}^{2}$. The electrical contact was copper wire. After the carbon paste was packed and before modification, the electrode surface was smoothed utilizing white, bond paper. CPE was modified either by the electropolymerization of FA or FA-GOx-BSA. At first, the electropolymerization of ferulic acid was carried out at different $\mathrm{pH}$ conditions in acetate medium. The presence of poly-FA membrane on a CPE was evaluated by cyclic voltammetry. The biosensing membranes were synthesized in acetates medium at neutral $\mathrm{pH}$ in a solution containing a monomer (FA), a biorecognition element (GOx), and an enzyme stabilizer (BSA). The membrane synthesis was performed by cyclic voltammetry at a scan rate of $20 \mathrm{mV} / \mathrm{s}$, from -600 to $850 \mathrm{mV}$ for 10 cycles.

To obtain the biosensor analytical parameters, the electrodes were evaluated through their response to glucose performing calibration. The glucose quantification was performed 
at constant potential by amperometry through successive glucose additions. Biosensor selectivity was evaluated for ascorbic acid as well as uric acid responses. First, the glucose biosensors were evaluated in PBS, and later, in the presence of proteins utilizing artificial interstitial fluid.

\section{Conclusions}

Concerning ferulic acid electropolymerization, the results obtained in this investigation have shown the feasibility of a poly-FA membrane synthesis in aqueous media at acidic, at basic, and also at neutral $\mathrm{pH}$, increasing the potential use of the polymeric membrane for the development of biosensing films.

We effectively synthesized a poly-FA-GOx-BSA biosensing membrane toward the development of amperometric glucose biosensors. The developed glucose biosensors exhibited a linear response in a dynamic range covering the hypo, normal, and hyperglycemic conditions showing favorable results concerning linearity improvement of glucose biosensors. Moreover, the biosensors showed a rapid response as well as good operational stability. Further, the results obtained on a-ISF were encouraging for biosensors used at real samples (biofluids). The versatility of the system would allow its implementation for other recognition elements in the direction of biosensors with applications in healthcare, the food industry, or environmental fields. Future work will be focused on improving analytical parameters employing other electrode materials, redox mediators, or permselective membranes to improve selectivity, stability, sensitivity, repeatability, shelf life, and linearity to be used on food samples without previous treatment. Morphological and structural biosensing membrane characterization studies will also be performed in future work.

Author Contributions: G.V.-R. performed the conceptualization, investigation, methodology, experimentation, formal data analysis, writing, and editing the manuscript. L.G. performed the conceptualization, funding acquisition, resources administration, reviewing, and editing the manuscript. All authors have read and agreed to the published version of the manuscript.

Funding: This research received no external funding.

Institutional Review Board Statement: Not applicable.

Informed Consent Statement: Not applicable.

Data Availability Statement: Not applicable.

Conflicts of Interest: The authors declare no conflict of interest.

\section{References}

1. Karyakin, A.A. Glucose biosensors for clinical and personal use. Electrochem. Commun. 2021, 125, 106973. [CrossRef]

2. Yoo, E.-H.; Lee, S.-Y. Glucose Biosensors: An Overview of Use in Clinical Practice. Sensors 2010, 10, 4558-4576. [CrossRef]

3. Teymourian, H.; Barfidokht, A.; Wang, J. Electrochemical glucose sensors in diabetes management: An updated review (20102020). Chem. Soc. Rev. 2020, 49, 7671-7709. [CrossRef] [PubMed]

4. Cavalcante, F.; de Falcão, I.A.; Souza, J.D.S.; Rocha, T.; de Sousa, I.; Cavalcante, A.; de Oliveira, A.; de Sousa, M.; dos Santos, J. Designing of nanomaterials-based enzymatic biosensors: Synthesis, properties, and applications. Electrochem $2021,2,12$. [CrossRef]

5. Curulli, A. Electrochemical Biosensors in Food Safety: Challenges and Perspectives. Molecules 2021, 26, 2940. [CrossRef] [PubMed]

6. Sassolas, A.; Blum, L.J.; Leca-Bouvier, B. Immobilization strategies to develop enzymatic biosensors. Biotechnol. Adv. 2012, 30, 489-511. [CrossRef]

7. Yáñez-Sedeño, P.; Campuzano, S.; Pingarrón, J. Screen-Printed Electrodes: Promising Paper and Wearable Transducers for (Bio)Sensing. Biosensors 2020, 10, 76. [CrossRef]

8. Komathi, S.; Gopalan, A.I.; Muthuchamy, N.; Lee, K.P. Polyaniline nanoflowers grafted onto nanodiamonds via a soft templateguided secondary nucleation process for high-performance glucose sensing. RSC Adv. 2017, 7, 15342-15351. [CrossRef]

9. Shen, Q.; Zheng, J. Bienzyme system for the biocatalyzed deposition of polyaniline templated by multiwalled carbon nano-tubes: A biosensor design. Biosens. Bioelectron. 2019, 15, 1621-2629. [CrossRef]

10. Madden, J.; Barret, C.; Laffir, F.; Thompson, M.; Galvin, P.; O’Riordan, A. On-chip glucose detection based on glucose oxidase encapsulated on a platinum modified gold microband electrode. Chemrxiv 2021. [CrossRef] 
11. Ahmad, W.; Verma, S.; Yang, D.-J.; Islam, M.U.; Choudhury, A. Synthesis of silver nanoparticles-decorated poly(m-aminophenol) nanofibers and their application in a non-enzymatic glucose biosensor. J. Macromol. Sci. Part A 2021, 1-17. [CrossRef]

12. Monti, P.; Bacciu, A.; Arrigo, P.; Marceddu, S.; Migheli, Q.; Serra, P.A.; Rocchitta, G. Chronoamperometry as effective alternative technique for electro-synthesis of ortho - phenylendiamine permselective films for biosensor applications. J. Appl. Polym. Sci. 2020, 137, 49172. [CrossRef]

13. Shrestha, B.K.; Ahmad, R.; Shrestha, S.; Park, C.H.; Kim, C.S. Globular shaped polypyrrole doped well-dispersed functionalized multiwall carbon nanotubes/nafion composite for enzymatic glucose biosensor application. Sci. Rep. 2017, 7, 1-13. [CrossRef] [PubMed]

14. Lai, J.; Yi, Y.; Zhu, P.; Shen, J.; Wu, K.; Zhang, L.; Liu, J. Polyaniline-based glucose biosensor: A review. J. Electroanal. Chem. 2016, 782, 138-153. [CrossRef]

15. Windmiller, J.R.; Valdés-Ramírez, G.; Zhou, N.; Zhou, M.; Miller, P.R.; Jin, C.; Brozik, S.M.; Polsky, R.; Katz, E.; Narayan, R.; et al. Bicomponent microneedle array biosensor for minimally-invasive glutamate monitoring. Electroanalysis 2011, 23, $2302-2309$. [CrossRef]

16. Buanafina, M.M.D.O. Feruloylation in grasses: Current and future perspectives. Mol. Plant 2009, 2, 861-872. [CrossRef]

17. Sohn, Y.T.; Oh, J.H. Characterization of physicochemical properties of ferulic acid. Arch. Pharmacal Res. 2003, $26,1002-1008$. [CrossRef]

18. Mattila, P.; Kumpulainen, J. Determination of free and total phenolic acids in plant-derived foods by HPLC with diode-array detection. J. Agric. Food Chem. 2002, 50, 3660-3667. [CrossRef]

19. Zduńska, K.; Dana, A.; Kolodziejczak, A.; Rotsztejn, H. Antioxidant properties of ferulic acid and its possible application. Ski. Pharmacol. Physiol. 2018, 31, 332-336. [CrossRef]

20. Cappelli, A.; Paolino, M.; Reale, A.; Razzano, V.; Grisci, G.; Giuliani, G.; Donati, A.; Bonechi, C.; Lamponi, S.; Mendichi, R.; et al. Hyaluronan-based graft copolymers bearing aggregation-induced emission fluorogens. RSC Adv. 2018, 8, 5864-5881. [CrossRef]

21. da Silva, L.V.; Lopes, C.B.; da Silva, W.C.; de Paiva, Y.G.; Silva, F.D.A.D.S.; Lima, P.R.; Kubota, L.T.; Goulart, M.O.F. Electropolymerization of ferulic acid on multi-walled carbon nanotubes modified glassy carbon electrode as a versatile platform for NADH, dopamine and epinephrine separate detection. Microchem. J. 2017, 133, 460-467. [CrossRef]

22. Bounegru, A.V.; Apetrei, C. Development of a novel electrochemical biosensor based on carbon nanofibers-gold nanoparticlestyrosinase for the detection of ferulic acid in cosmetics. Sensors 2020, 20, 6724. [CrossRef]

23. Matsushita, Y.; Nakamura, A.; Aoki, D.; Yagami, S.; Fukushima, K. Bio-based polymer from ferulic acid by electropolymerization. Bioresources 2016, 11, 9789-9802. [CrossRef]

24. Xia, Z. Electrochemical determination of ferulic acid in pinellia ternata based on GOs/MWCNTs nanocomposite modified electrode. Int. J. Electrochem. Sci. 2020, 15, 559-566. [CrossRef]

25. Trabelsi, S.K.; Tahar, N.B.; Trabelsi, B.; Abdelhedi, R. Electrochemical oxidation of ferulic acid in aqueous solutions at gold oxide and lead dioxide electrodes. J. Appl. Electrochem. 2005, 35, 967-973. [CrossRef]

26. Graf, E. Antioxidant potential of ferulic acid. Free Radic. Biol. Med. 1992, 13, 435-448. [CrossRef]

27. Barsan, M.M.; Ghica, M.E.; Brett, C.M. Electrochemical sensors and biosensors based on redox polymer/carbon nanotube modified electrodes: A review. Anal. Chim. Acta 2015, 881, 1-23. [CrossRef]

28. Samet, Y.; Kraiem, D.; Abdelhédi, R. Electropolymerization of phenol, o-nitrophenol and o-methoxyphenol on gold and carbon steel materials and their corrosion protection effects. Prog. Org. Coat. 2010, 69, 335-343. [CrossRef]

29. Ayankojo, A.G.; Reut, J.; Ciocan, V.; Öpik, A.; Syritski, V. Molecularly imprinted polymer-based sensor for electrochemical detection of erythromycin. Talanta 2020, 209, 120502. [CrossRef] [PubMed]

30. Fogh-Andersen, N.; Altura, B.M.; Siggaard-Andersen, O. Composition of interstitial fluid. Clin. Chem. 1995, 41, 1522-1525. [CrossRef]

31. Mader, J.K.; Neubauer, K.M.; Schaupp, L.; Augustin, T.; Beck, P.; Spat, S.; Höll, B.; Treiber, G.M.; Fruhwald, F.M.; Pieber, T.R.; et al. Efficacy, usability and sequence of operations of a workflow-integrated algorithm for basal-bolus insulin therapy in hospitalized type 2 diabetes patients. Diabetes Obes. Metab. 2013, 16, 137-146. [CrossRef] [PubMed] 